\title{
Olfactory Dysfunction Among Asymptomatic Patients with SARS CoV2 Infection: A Case-Control Study
}

\author{
Vishal Mangal $^{1} \cdot$ T. Murari ${ }^{1} \cdot$ Rohit Vashisht $^{1} \cdot$ Shaik Mohammad Iqbal $^{1} \cdot$ Kodavati Meghana $^{1} \cdot$ Sagar Gujrathi $^{2} \cdot$ \\ Vivek Ambade $^{3} \cdot$ TVSVGK Tilak $^{1} \cdot$ Vivek Aggarwal $^{1} \cdot$ Manish Manrai $^{1} \cdot$ Vishesh Verma $^{1} \cdot$ Rajagopal Srinath $^{1}$. \\ Nidhi Goel ${ }^{1} \cdot$ Navin Kumar Yadav ${ }^{1} \cdot$ Anil Menon $^{1}$
}

Received: 7 December 2020/ Accepted: 4 January 2021/Published online: 10 February 2021

(C) Association of Otolaryngologists of India 2021

\begin{abstract}
Olfactory dysfunction (hyposmia, anosmia) is a well-recognized symptom in patients with coronavirus disease-19 (COVID-19). Studies of olfactory dysfunction in asymptomatic patients have not been reported. We conducted a study looking for the presence of olfactory dysfunction with an objective assessment tool in asymptomatic Covid 19 and compared it with patients with mild COVID-19 and age-matched controls. We recruited 57 male patients each of Mild COVID-19, asymptomatic Covid 19, and healthy controls for the study. All participants underwent evaluation of smell threshold by Butanol Threshold test (BTT) and ability to distinguish common odors by Smell identification test. The scores of each test
\end{abstract}

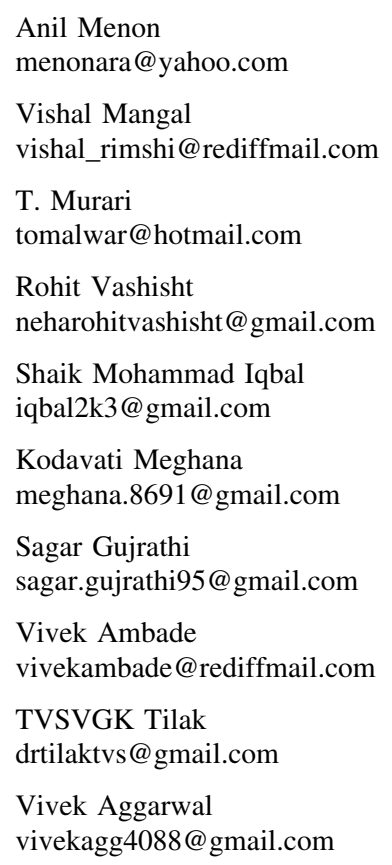

were recorded on a numerical scale. The participants in all three arms were matched for age, history of smoking, and pre-existing medical conditions. The mean scores of the Butanol Threshold test in Mild COVID-19, asymptomatic Covid 19 and controls were $2.95 \pm 2.25$ (0-7.5), $3.42 \pm 2.23(0-7.5)$, and $4.82 \pm 1.86(0-8)$, respectively. A one-way ANOVA showed a significant difference between groups (df 2, MS 53.78, F 11.94, $p<0.005$ ). Intergroup differences using the student $\mathrm{T}$-test showed significantly low BTT scores in Mild COVID-19 $(p<0.005)$ and asymptomatic $(p<0.005)$ as compared to control. BTT scores could not distinguish between

Manish Manrai

manishmanrai@outlook.com

Vishesh Verma

visheshverma@live.com

Rajagopal Srinath

srinath290775@gmail.com

Nidhi Goel

nidhigoe10805@gmail.com

Navin Kumar Yadav

navyn18041987@gmail.com

1 Department of Internal Medicine, Armed Forces Medical College, Pune, Maharashtra 411040, India

2 Department of Otorhinolaryngology \& Head and Neck Surgery, Armed Forces Medical College, Pune, Maharashtra 411040, India

3 Department of Biochemistry, Armed Forces Medical College, Pune, Maharashtra 411040, India 
asymptomatic patients and control. The smell threshold was impaired in asymptomatic Covid 19 and Mild COVID19. Butanol Threshold Test score could not differentiate between asymptomatic Covid 19 and controls.

Keywords Olfactory dysfunction - Asymptomatic . COVID-19 - SARS CoV2 $\cdot$ Butanol threshold testing

\section{Introduction}

Olfactory dysfunction (OD) as a symptom of COVID-19 was recognized early on in the pandemic [1]. Cross-sectional studies in symptomatic patients of COVID-19 have reported the prevalence of OD like hyposmia (partial loss of smell) and anosmia (complete lack of smell) to be ranging from 19 to $90 \%$ [2-4].The prevalence of OD in COVID- 19 has been shown to have no correlation with the severity of the disease [5].OD in patients of COVID-19 has either been self-reported or has been studied using questionnaires. Questionnaires have mostly been non-validated except one which used Sino-nasal Outcome Test (SNOT22) [6]. A couple of studies have utilized objective measures for assessing OD, like the University of Pennsylvania Smell Identification Test (UPSIT) and Butanol Threshold test (BTT) [5,7]. A recent systematic review and metaanalysis of methods used in assessing OD in patients found that the pooled prevalence estimate of OD was $45 \%$ with subjective methods and $77 \%$ by objective methods in patients with COVID-19 [8]. The Connecticut Chemosensory Clinical Research Centre has described the use of butanol to test for olfactory threshold. The pure form of butanol can be diluted to achieve the desired concentration and can be used objectively to determine the olfactory threshold [9]. Since the beginning of the pandemic, there have been reports of patients infected with SARS CoV2 infection but who did not develop symptoms (asymptomatic) [10]. World Health Organisation defines asymptomatic COVID-19 as laboratory-confirmed infected individuals without overt symptoms [11]. We aimed to assess the prevalence of OD using BTT in asymptomatic patients and patients with mild COVID-19 and compare them with age-matched controls. We also used common odors for qualitative assessment of $\mathrm{OD}$ in asymptomatic patients, mild COVID-19 patients and controls.

\section{Materials and Methods}

\section{Study Setting}

The Institutional ethical committee approved the study. The study participants were all males more than 18 years of age, and it was conducted at two designated COVID hospitals and a single COVID Community Care center in western India from 16 to 26 November 2020. The control group consisted of age-matched healthy male volunteers who were mainly health care workers released from quarantine and proven to be RT-PCR negative at the end of quarantine.

\section{Study Design}

The design was case-control, where asymptomatic COVID-19 and mild COVID-19 patients were compared with healthy controls in a 1:1:1 ratio.

\section{Sample Size}

Based on the data from previous studies, the sample size required was 31 in each arm of the study (assuming 80\% power, $5 \%$ significance level with $95 \%$ confidence interval, and assuming 10\% margin of error). Inclusion Criteria: (i) Asymptomatic individuals positive for SARS-COV2 by RTPCR. (ii) Patients with Mild COVID-19 disease defined as patients not requiring oxygen. Exclusion criteria (i) Patients with Moderate \& Severe COVID-19 (ii) history of nasal polyps, allergic rhinitis (iii) history of neurosurgery or maxillofacial surgery (iv) history of head trauma (v) Asymptomatic patients who developed symptoms within 14 days after being detected positive (presymptomatic).

\section{Methodology}

The demographic characteristics, clinical features, comorbidities, and the onset of symptoms, were recorded by two researchers. This was followed by a quantitative and qualitative assessment of olfactory function using BTT and smell identification test respectively by a single researcher to avoid inter-observer bias.

\section{Study Protocol}

\section{Butanol Threshold Test}

Serial dilutions of 1-Butanol were prepared using deionized water. The maximum concentration of 1-butanol was 
$4 \%$, and the minimum concentration used was $0.0006 \%$. (Table 1). We used the template as described by Cain W S et al. [9]. After informed consent, subjects were asked to smell serial dilutions of butanol and deionized water alternatively from minimum to maximum concentration. The test solution was presented in a $100 \mathrm{ml}$ amber colored glass bottle containing $50 \mathrm{ml}$ of the test solution. To perform the test, the cap of the bottle containing butanol or deionized water was removed by the examiner for $3 \mathrm{~s}$, and the mouth of the bottle was placed $2 \mathrm{~cm}$ in front of each nostril, and the patient was asked to sniff usually without any force through each nostril. The lowest concentration of butanol that the patient identified was defined as the threshold. Scores of one to nine were given from highest to the lowest concentration of solution successfully identified. The scores of each nostril were recorded separately, and an average score of both the nostrils was taken as the final score of the patient. The patient who failed to identify even the maximum concentration of the butanol was scored as zero.

\section{Smell Identification Test}

The list of substances chosen was based on routine use in the study population and is in Table 2 . The substances were kept in opaque plastic bottles. The subject was requested to close his eyes to prevent any chance of visual identification. To perform the test, the examiner removed the cap for $3 \mathrm{~s}$, and the mouth of the bottle was placed $2 \mathrm{~cm}$ in front of the nostril, and the patient was asked to sniff usually without any force. An interval of at least $30 \mathrm{~s}$ was maintained between successive presentations to prevent olfactory desensitization. Patients were asked to choose from a list of four choices for each substance presented. Each correct identification was given a score of 1 , and incorrect identification was scored as 0 .

Table 1 Concentration of Butanol and Score assigned

\begin{tabular}{lll}
\hline Dilution step & Butanol concentration $(\%)$ & Score \\
\hline 1 & 4.0000 & 1 \\
2 & 1.3333 & 2 \\
3 & 0.4444 & 3 \\
4 & 0.1481 & 4 \\
5 & 0.0494 & 5 \\
6 & 0.0165 & 6 \\
7 & 0.0055 & 7 \\
8 & 0.0018 & 8 \\
9 & 0.0006 & 9 \\
\hline
\end{tabular}

\section{Statistical Analysis}

Statistical analysis was performed with Microsoft Excel. Continuous variables were expressed as mean $\pm \mathrm{SD}$ (95\% confidence interval). We studied the association of OD with other symptoms by performing cross-tabulation. The difference between groups was analyzed using ANOVA. The student's T-test was used to make withingroup comparisons. A $p$-value of $<0.05$ was considered significant. We also constructed a ROC using BTT scores of participants with Mild COVID-19 and asymptomatic group to study the sensitivity and false positivity to see if BTT scores could differentiate them from controls.

\section{Results}

We recruited 57 individuals for each arm of the study. The baseline data of the participants are shown in Table 3. The most common symptoms in patients with Mild COVID-19 were fever $(53.2 \%)$, sore throat $(37.1 \%)$, cough $(21 \%)$, rhinorrhea $(24.2 \%)$, body ache $(24.2 \%)$, and headache $(17.7 \%)$. Olfactory dysfunction in the form of hyposmia and anosmia was reported by $17.7 \%$ and loss of taste by 12.9\%.In patients with mild COVID-19, BTT and SIT were done $12.46 \pm 5.41$ (range 1-24) days after onset of symptoms. In asymptomatic patients, BTT \& SIT was done $8.45 \pm 6.35$ (range 0-24) days after being detected positive for SARS CoV2. BTT and SIT were done in controls on the same day they were recruited. The results of BTT and SIT in the three groups are depicted in Figs. 1, 2. A one-way Analysis of Variation (ANOVA) of BTT scores was performed in the three groups and showed a significant difference (df 2, MS 53.78, F 11.94, $p<0.005$ ). A difference of lesser degree within groups but still significant was found in SIT (df 2, MS 7.61, F 3.28, $p=0.04$ ). We used the Students T-test to calculate inter group differences of BTT score. The BTT scores of Mild COVID-19 were significantly lower than control. $(p<0.005)$. Similarly, BTT scores of asymptomatic participants were significantly lower than controls $(p<0.005)$. However, the difference of BTT scores between Mild COVID-19 and asymptomatic patients was not significant $(p=0.26)$. By plotting the ROC curve using BTT scores of Mild COVID19 and asymptomatic, no BTT value could help differentiate Mild Covid or asymptomatic patients from controls. SIT scores of asymptomatic individuals were lower than controls $(p=0.02)$. There was no significant difference in SIT scores of Mild COVID-19 and controls. 
Table 2 Odors used for smell identification test

\begin{tabular}{l} 
Naphthalene \\
\hline Pine apple \\
Mango ripe \\
Rose water \\
Cumin \\
Asafetida \\
Cardamom
\end{tabular}

\section{Discussion}

Olfactory functions can be categorized as normal, hyposmia (partial loss of smell), and anosmia (complete loss of smell). Evaluation for OD is commonly done by testing for olfactory threshold and ability to identify familiar odors. Odor identification has an inherent drawback that odors presented are supra-threshold and hence lack sensitivity. On the other hand, testing for odor threshold measures olfactory sensitivity; however, it is time-consuming and tests only for one particular odor [12]. Specially designed tests like UPSIT, 'Sniffin Sticks,' Cross-Cultural Smell
Identification Test are proprietary and not readily available in India [13-15]. We used BTT as it is well validated to detect olfactory threshold. Butanol is readily available, water-soluble, safe, has neutral odor, serial dilutions can be prepared in the laboratory, and stable concentrations are maintained for a long time.

Our study showed significant OD in Mild COVID-19 compared to controls. Moein et al. studied olfactory dysfunction in sixty symptomatic patients with COVID-19 using UPSIT and compared them with controls. Twentyone patients $(35 \%)$ reported a loss of taste or smell functions. They found OD of varying degree in fifty nine $(98 \%)$ patients as against eleven $(18 \%)$ controls $(p<0.0001)$. Twenty-five patients (42\%) had mild COVID-19, and olfactory dysfunction did not correlate with disease severity [5]. Chung et al. studied olfactory dysfunction using BTT in eighteen patients of Mild COVID-19 and compared them with age-matched control. The mean BTT score of patients with COVID-19 was lower than control. $(p=0.004)$ [7].

In our study, asymptomatic patients were shown to have a significant prevalence of OD compared to controls (Fig. 1). They were assessed $8.45 \pm 6.35$ (range 0-24) days after being detected to be positive for SARS

Table 3 Baseline characteristic of study participants

\begin{tabular}{llll}
\hline & Mild Covid 19 $(\mathrm{n}=57)$ & Asymptomatic $(\mathrm{n}=57)$ & Control $(\mathrm{n}=57)$ \\
\hline Age (years) & & & 34 \\
$15-29$ & 25 & 33 & 21 \\
$30-39$ & 24 & 12 & 2 \\
$40-49$ & 6 & 11 & 0 \\
$>50$ & 2 & 1 & 12 \\
H/o smoking & 19 & 13 & 12 \\
\hline
\end{tabular}

Fig. 1 Result of Butanol threshold test in various groups
Butanol Threshhold Test

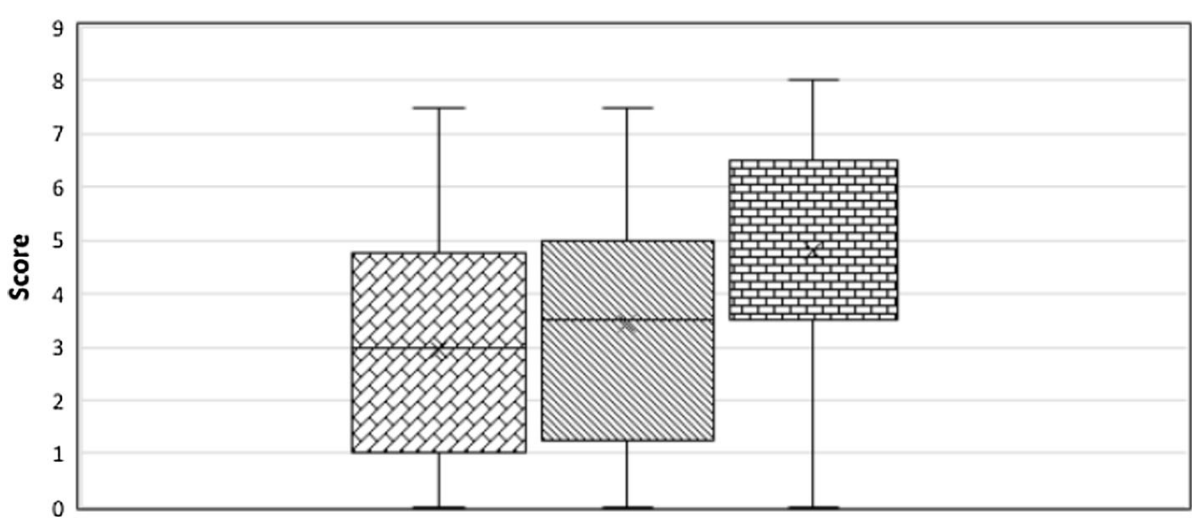

Mild Covid $\mathbb{Q}$ Asymptomatic $⿴ 囗 十$ Control 
Fig. 2 Result of Smell identification test in various groups
Smell Identification Test

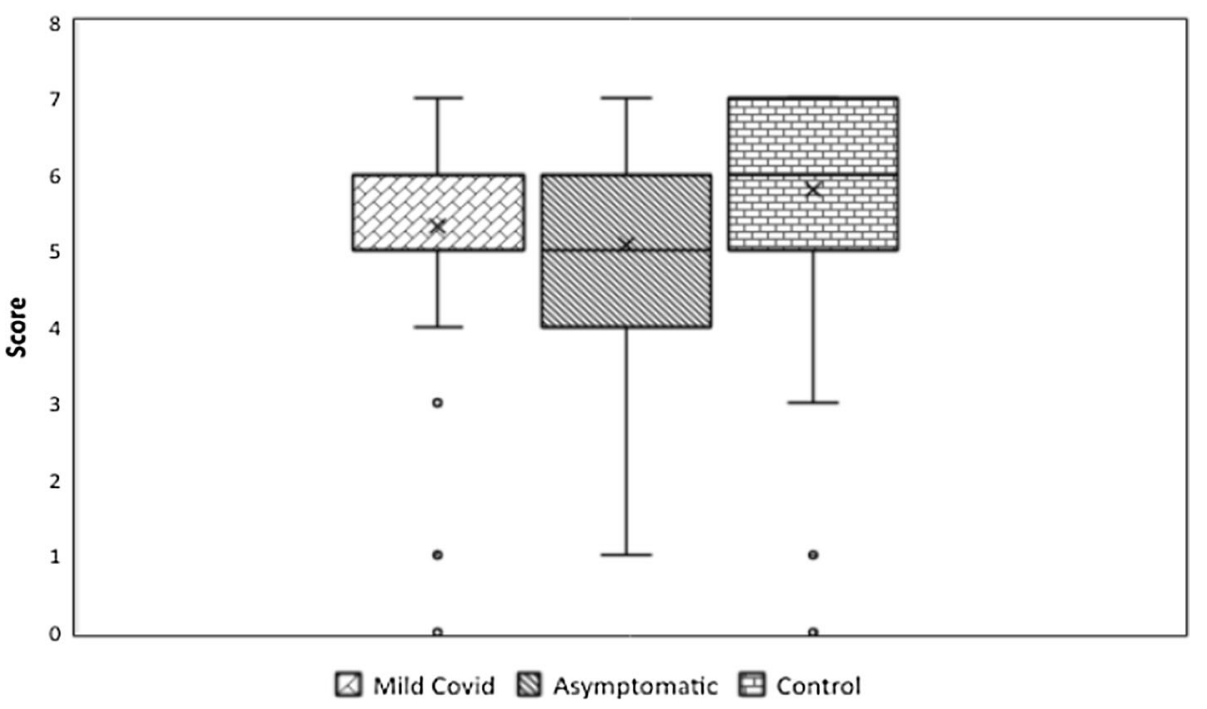

CoV2. We monitored them for the development of symptoms; those who remained asymptomatic were included in the analysis. Asymptomatic infections account for $40-45 \%$ of total SARS CoV2 infections and can transmit the virus for fourteen days or more, which makes them the main drivers of the COVID-19 pandemic [10].Hence identification of asymptomatic patients is vital for infection control. Short of screening for the presence of SARS CoV2, no lab parameter can identify asymptomatic individuals.

We could not define a BTT score which could reliably distinguish OD in asymptomatic Covid 19 or Mild Covid 19 from controls. Experts caution against the use of smell testing for screening of COVID-19, as a symptom of anosmia has low sensitivity in the diagnosis of COVID-19, and anosmia can persist up to eight weeks in approximately $10 \%$ of cases. Also, OD is found in the general population with increased prevalence with increasing age [16].

The pathophysiology of anosmia in COVID-19 is a subject of intense research. SARS CoV2 binds to angiotensin-converting enzyme 2 (ACE2) and transmembrane protease serine 2 (TMPRSS2) moiety on host cells to gain entry [17]. Gupta et al. did a bioinformatic analysis of single-gene expression and protein interactions across various olfactory epithelium cell types. They concluded that a subset of sustentacular (supporting) cells and not olfactory receptor neurons as the most vulnerable cell to SARS Cov2 infection [18]. Sustenacular cells function as glial cells and are involved in physically and chemically insulating olfactory receptor neurons and regulate the extracellular ionic environment [19].

COVID-19 presents with a spectrum from asymptomatic to severe disease. It has been hypothesized that this is due to numerous factors, which affect the pathogenicity of the SARS CoV2 virus and individual
susceptibility.[20]Olfactory dysfunction occurring in asymptomatic and Mild COVID-19 argues for a common mechanism like dysfunction of sustentacular cells of olfactory epithelium by direct invasion. Our study's strength was its case-control design, rigorous follow-up of asymptomatic patients, and use of objective measure to detect olfactory dysfunction. The study's limitation was the inclusion of only male participants; hence generalisability is hampered, and a higher number of smokers in the group with Mild Covid 19.

\section{Conclusion}

We found significant olfactory dysfunction in a cohort of male individuals with asymptomatic Covid 19 when assessed by Butanol Threshold test. However, Butanol Threshold Test scores could not reliably distinguish asymptomatic Covid 19 from controls.

\section{Acknowledgement NIL}

Authors' Contribution All authors contributed to the study conception and design. Material preparation, data collection and analysis were performed by [AS Menon, Vishal Mangal, Shaik Mohammad Iqbal, Kodavati Meghana, Sagar Gujrathi,Vivek Ambade,]. The first draft of the manuscript was written by [AS Menon and, Vishal Mangal] and all authors commented on previous versions of the manuscript. All authors read and approved the final manuscript.

Funding The study was funded by the Department of Internal Medicine.

\section{Compliance with Ethical Standards}

Conflicts of interest All the authors declare that there is no conflict of interest. 
Consent to Participate Informed written consent was taken from all the study participants.

Consent for Publication Written informed consent for publication of their clinical details was obtained from the patient.

Ethics Approval The study was approved by the institutional ethical committee vide IEC S.No:EC/2020/330.

\section{References}

1. Menni C, Valdes A, Freydin MB, Ganesh S, Moustafa JES, Visconti A et al (2020) Real-time tracking of self-reported symptoms to predict potential COVID-19. Nat Med 26:1037-1040

2. Bagheri SH, Asghari A, Farhadi M, Shamshiri AR, Kabir A, Kamrava SK et al (2020) Coincidence of COVID-19 epidemic and olfactory dysfunction outbreak in Iran. Med J Islam Repub Iran 34:62. https://www.ncbi.nlm.nih.gov/pmc/articles/PMC7 500422/. Accessed 30 Nov 2020

3. Lechien JR, Chiesa-Estomba C, De Siati DR, Horoi M, Le Bon SD, Rodriguez A (2020) Olfactory and gustatory dysfunctions as a clinical presentation of mild to moderate forms of the coronavirus disease (COVID-19): a multicenter european study. Eur Arch Otorhinolaryngol 277(8):2251-2261

4. Beltrán-Corbellini A, Chico-García J, Martínez-Poles J, Rodríguez-Jorge F, Natera-Villalba E, Gómez-Corral J (2020) Acuteonset smell and taste disorders in the context of COVID-19: a pilot multicenter polymerase chain reaction based case-control study. Eur J Neurol 27:1738-1741

5. Moein ST, Hashemian SMR, Mansourafshar B, Khorram-Tousi A, Tabarsi P, Doty RL (2020) Smell dysfunction: a biomarker for COVID-19. Int Forum Allergy Rhinol 10:944-950

6. Spinato G, Fabbris C, Polesel J, Cazzador D, Borsetto D, Hopkins C, Boscolo-Rizzo P (2020) lterations in smell or taste in mildly symptomatic outpatients with SARS-CoV-2 infection. JAMA 323(20):2089-2090

7. Chung TW, Sridhar S, Zhang AJ, Chan K, Li H, Wong FK (2020) Olfactory dysfunction in coronavirus disease 2019 patients: observational cohort study and systematic review. Open Forum Infect Dis [serial on the Internet].2020 Jun. Available from: https://www.ncbi.nlm.nih.gov/pmc/articles/PMC7284010/, accessed on 30 November, 2020

8. Hannum ME, Ramirez VA, Lipson SJ, Herriman RD, Toskala AK, Lin C et al. (2020) Objective sensory testing methods reveal a higher prevalence of olfactory loss in COVID-19-positive patients compared to subjective methods: a systematic review and meta-analysis. Chem Senses[serial on the Internet].2020 Sep. Available from: https://www.ncbi.nlm.nih.gov/pmc/articles/ PMC7543258/, accessed on 30 November, 2020
9. Cain WS, Gent JF, Goodspeed RB, Leonard G (1988) Evaluation of olfactory dysfunction in the connecticut chemosensory clinical research center. Laryngoscope 98:83-88

10. Oran DP, Topol EJ (2020) Prevalence of asymptomatic SARSCoV-2 infection. A Narrative Review Ann Intern Med [serial on the Internet]. 2020 Jun. Available from: https://www.ncbi.nlm. nih.gov/pmc/articles/PMC7281624/, accessed on 30 November, 2020

11. Clinical management of COVID-19 [Internet]. Who.int. 2020 [cited 1 December 2020]. Available from: https://www.who.int/ publications/i/item/clinical-management-of-covid-19

12. Boesveldt S, Postma EM, Boak D, Welge-Luessen A, Schöpf V, Mainland JD et al (2017) Anosmia-a clinical review. Chem Sens 42:513-523

13. Doty RL, Shaman P, Kimmelman CP, Dann MS (1984) University of Pennsylvania smell identification test: a rapid quantitative olfactory function test for the clinic. Laryngoscope 94:176-178

14. Cobal G, Hummel T, Sekinger B, Barz S, Roscher S, Wolf S (1996) Sniffin sticks: screening of olfactory performance. Rhinology 34(4):222-226

15. Doty RL, Marcus A, Lee WW (1996) Development of the 12 -item cross cultural smell identification test (CC-SIT). Laryngosope 106:222-226

16. Hopkins C, Smith B (2020) Widespread smell testing for COVID-19 has limited application. Lancet 6736(20):32317-32325

17. Hoffmann M, Kleine-Weber H, Schroeder S, Krüger N, Herrler $\mathrm{T}$, Erichsen S et al (2020) SARS-CoV-2 cell entry depends on ACE2 and TMPRSS2 and is blocked by a clinically proven protease inhibitor. Cell 181:271-280

18. Gupta K, Mohanty SK, Mittal A, Kalra S, Kumar S, Mishra T et al. (2020) The Cellular basis of loss of smell in 2019-nCoVinfected individuals. Brief Bioinform [serial on the Internet]. 2020 Aug. Available from: https://europepmc.org/article/med/ 32810867, accessed on 30 November, 2020

19. Breipohl W, Laugwitz HJ, Bornfeld N (1974) Topological relations between the dendrites of olfactorysensory cells and sustenacular cells in different vertebrates. An ultrastructural study. J Anat 117:89-94

20. Mayorala EP, Hernandez-Huertab MT, Mayorala LP, MatiasCervantesb CA,Mayoral-Andradea G, Barriosc LAL, PerezCamposc E. (2020) Factors related to asymptomatic or severe COVID-19 infection. Med. Hypotheses [serial on the Internet]. 2020 Sep. Available from: https://www.ncbi.nlm.nih.gov/pmc/ articles/PMC7513914/, accessed on 30 Nov, 2020

Publisher's Note Springer Nature remains neutral with regard to jurisdictional claims in published maps and institutional affiliations. 